\title{
Epidemiology and economic burden of herpes zoster and post-herpetic neuralgia in Italy: A retrospective, population-based study
}

Leonardo Emberti Gialloreti ${ }^{*}$, Monica Merito ${ }^{2}$, Patrizio Pezzotti ${ }^{2}$, Luigi Naldi ${ }^{3}$, Antonio Gatti ${ }^{4}$, Maud Beillat ${ }^{5}$, Laurence Serradell ${ }^{5}$, Rafaelle di Marzo ${ }^{6}$, Antonio Volpi ${ }^{1}$

\begin{abstract}
Background: Data on the epidemiology and cost of herpes zoster ( $\mathrm{HZ})$ and post-herpetic neuralgia (PHN) in Italy are limited. This retrospective, population-based study was designed to determine the incidence of $\mathrm{HZ}$ and the proportion developing PHN in Italy and the associated medical resource utilisation and costs. It focused primarily on immunocompetent patients aged $\geq 50$ years who would be eligible for preventive vaccination.
\end{abstract}

Method: Data were extracted from a primary-care database and national hospital-discharge records covering four major regions in Italy for 2003-2005. Cases of HZ and PHN (1 and 3 months' duration; PHN1 and PHN3) were identified by ICD9-CM codes and, additionally for PHN, prescription of neuropathic pain medication.

Results: Over 3 years, 5675 incident cases of $\mathrm{HZ}$ were documented in adults, of which 3620 occurred in immunocompetent patients aged $\geq 50$ years (incidence of 6.31 per 1000 person-years [95\% Cl: 6.01-6.62]). Of the immunocompetent patients aged $\geq 50$ years with $\mathrm{HZ}$, 9.4\% (95\% Cl: 8.2-10.7) and 7.2\% (95\% Cl: 6.2-8.2) developed PHN1 and PHN3, respectively. Increasing age, female sex, and being immunologically compromised conferred increased risk for both $\mathrm{HZ}$ and PHN. Overall, about 1.3\% of $\mathrm{HZ}$ and almost 2\% of PHN cases required inpatient care, with $16.9 \%$ of all $\mathrm{HZ}$-related hospitalisations due specifically to PHN. In patients aged $\geq 50$ years, mean stay was $7.8 \pm 5.4$ days for $\mathrm{HZ}$ and $10.2 \pm 8.6$ days for PHN, and direct costs associated with inpatient care were more than 20 times outpatient costs per HZ case (mean \pm SD: $€ 2592 \pm € 1313$ vs. $€ 122.68 \pm € 97.51$ ) and over 5 times more per episode of PHN (mean \pm SD: $€ 2806 \pm € 2641$ vs. $€ 446.10 \pm € 442.97)$ ). Total annual costs were $€ 41.2$ million, of which $€ 28.2$ million were direct costs and $€ 13.0$ million indirect costs.

Conclusions: This study, the largest to date on the epidemiology and economic impact of $\mathrm{HZ}$ and PHN in Italy, confirms the considerable disease and economic burden posed by $\mathrm{HZ}$. As $\mathrm{HZ}$ and PHN disproportionately affect the elderly, without intervention this problem is likely to grow as the proportion of elderly in the Italian population continues to increase.

\section{Background}

Herpes zoster (HZ), caused by reactivation of latent varicella zoster virus present in the dorsal root ganglia, is an acute disease characterised by a vesicular rash. The lifetime risk of developing $\mathrm{HZ}$ is about $20-30 \%$ [1-3]. However, the risk rises markedly with age, approximately doubling for each decade after 50 years of age [4]. This age-related increase in HZ, which can occur

\footnotetext{
* Correspondence: leonardo.emberti.gialloreti@uniroma2.it
${ }^{1}$ Dipartimento di Sanità Pubblica, Università di Roma Tor Vergata, Via

* Correspondence: leonardo.emberti.gialloreti@uniroma2.it
${ }^{1}$ Dipartimento di Sanità Pubblica, Università di Roma Tor Vergata, Via Montpellier 1, 00133, Roma, Italy
} Montpelier 1,00133, Roma, Italy

\section{()

decades after primary varicella zoster infection, is due to a varicella zoster virus-specific decline in cell-mediated immunity with increasing age [5].

While pain associated with the acute infection tends to resolve with the rash, post-herpetic neuralgia (PHN), an intractable pain in the dermatome affected by HZ, remains a common complication. Precise definitions of PHN vary, but it is estimated to affect $10-20 \%$ of all patients with $\mathrm{HZ}$ aged $>50$ years [6-8] and up to $30 \%$ of those aged $\geq 80$ years [6]. Pain associated with acute HZ infection and more especially PHN causes distress and 
adversely impacts patients' quality of life [9-14]. Moreover, the management of $\mathrm{HZ}$ and particularly PHN, the most common complication in the elderly, is often suboptimal $[15,16]$.

After Japan, Italy has the highest proportion of elderly people in its population [17], and yet data on the epidemiology of HZ and PHN in Italy and the associated costs are limited. An observational study carried out a decade ago in Italy noted an incidence of 4.14 per 1000 population (aged $\geq 15$ years) per year. In that study, over $75 \%$ of all HZ cases occurred in those aged $\geq 50$ years, with about $50 \%$ occurring in the $\geq 65$-year age group [18]. A more recent prospective Italian study found an annual incidence of 1.59 per 1000 population (aged $\geq 15$ years), and calculated a mean cost for each $\mathrm{HZ}$ case treated in the outpatient setting of $€ 360.60$ and for each hospitalised case of $€ 4082.59$ [19].

The present study was designed to provide additional data on the incidence of $\mathrm{HZ}$ and to determine the proportion of HZ cases developing PHN in Italy. The study also sought to determine the associated medical resource utilisation and costs, and to estimate the total economic burden of $\mathrm{HZ}$ and PHN in Italy. Both parts of the study focused on the immunocompetent population aged $\geq 50$ years, who would be eligible to receive a preventive vaccine that will be available soon in the European Union.

\section{Methods}

\section{Study design}

This was a retrospective, population-based study in which epidemiological and economic data were estimated in adult men and women, primarily aged $\geq 50$ years, from a large primary-care database and national hospital-discharge records.

\section{Data sources}

Primary-care data were obtained from the Health Search Database (HSD) of the Società Italiana Medici Generici (SIMG) for the period 2003-2005. Established in 1998, and with the input of general practitioners (GPs) who accept to participate on a voluntary basis, the SIMG database contains demographic data, medical diagnoses (coded according to the International Classification of Diseases, $9^{\text {th }}$ Revision, Clinical Modification [ICD9$\mathrm{CM}]$ ), drug prescriptions (coded according to the Anatomical Therapeutic Chemical [ATC] classification system), hospital referrals and diagnostic investigations for over 1 million patients [20,21]. This database has been set up by SIMG with the primary aim of carrying out observational studies on incidence and prevalence, as well as studies on drug safety and prescriptions. Data are recorded in the HSD with the consent of the patient, lawfully stored, managed according to privacy rules and can be used for scientific studies without any further authorization from an ethics committee.

The HSD, at the beginning of 2006, contained information from over $600 \mathrm{GPs}$, who were working in the national public health system, and were from the three major Italian geographical areas (Northern, Central, Southern Italy). The present study included a sample of 342 of these GPs who had contributed medical records to the HSD between 2003-2005. All physicians met standard quality criteria for the HSD [21]. Their geographic distribution mirrored the total population of these three geographical areas (152 from Northern Italy, 64 from Central Italy, and 126 from Southern Italy). The 342 physicians participating in this study represented around $0.8 \%$ of the total number of Italian GPs, covering approximately 450,000 patients, of which about 200,000 were aged $\geq 50$ years.

Each participating GP underwent formal training for data entry and used standard software to record data. A unique patient code links demographic and prescription information, clinical events and diagnoses, hospital admission, and cause of death. Data were subject to a range of quality checks.

The primary-care data were supplemented with data from hospital-discharge registries for the period 20032005 to determine hospitalisations due to HZ and PHN. Established in 1995 and covering all regions of Italy, the registries use a standard discharge form (Scheda di Dismissione Ospedaliera; SDO) to document patient demographic data, admission and discharge dates, discharge status, diagnostic/therapeutic procedures, discharge primary and secondary diagnoses (coded according to ICD9-CM), and in-hospital transfers. The SDO is the main source of information about hospital admissions in Italy, and all hospital discharges must also be registered, since SDO data contribute to the determination of the appropriate DRG and computation of the reimbursement fee for each hospitalization. Analogous to the HSD, the SDO data are also recorded with the consent of the patient, and can be used as aggregated data for scientific studies without further authorizations.

For the purpose of this study, registries of a representative sample of four regions (Veneto, Toscana, Lazio and Campania), which account for about $30 \%$ of the Italian population, were analysed. These regions were chosen as they mirror the three main Italian geographical areas (Northern, Central, and Southern Italy).

\section{Case definitions used to identify $\mathrm{HZ}$ cases in the databases}

The overall population of patients included in the analyses of primary-care data were those diagnosed with HZ in years 2003-2005 as defined by ICD9-CM codes (Table 1). To identify the immunocompetent subpopulation, we excluded patients with $\mathrm{HZ}$ who had received 
Table 1 International Classification of Diseases (ICD9-CM) Codes for Herpes Zoster and Related Complications

\begin{tabular}{|c|c|c|c|}
\hline Code Number & Medical Term & & \\
\hline \multirow[t]{18}{*}{053} & & & Herpes zoster (includes shingles zona) \\
\hline & 053.0 & & Herpes zoster with meningitis \\
\hline & 053.1 & & Herpes zoster with other nervous system complications \\
\hline & & 053.10 & Herpes zoster with unspecified nervous system complication \\
\hline & & 053.11 & Geniculate herpes zoster/Herpetic geniculate ganglionitis \\
\hline & & 053.12 & Post-herpetic trigeminal neuralgia \\
\hline & & 053.13 & Post-herpetic polyneuropathy \\
\hline & & 053.19 & Other \\
\hline & 053.2 & & Herpes zoster with ophthalmic complications \\
\hline & & 053.20 & Herpes zoster dermatitis of eyelid/herpes zoster ophthalmicus \\
\hline & & 053.21 & Herpes zoster keratoconjunctivitis \\
\hline & & 053.22 & Herpes zoster iridocyclitis \\
\hline & & 053.29 & Other \\
\hline & 053.7 & & Herpes zoster with other specified complications \\
\hline & & 053.71 & Otitis externa due to herpes zoster \\
\hline & & 053.79 & Other \\
\hline & 053.8 & & Herpes zoster with unspecified complication \\
\hline & 053.9 & & Herpes zoster without mention of complication (also known as herpes zoster NOS) \\
\hline
\end{tabular}

NOS $=$ not otherwise specified

immunosuppressive or immunomodulating drugs for a period of more than 3 months, and those who had been given the following ICD9-CM codes indicative of immunodeficiency; 042 (human immunodeficiency virus), 140-171, 174-208, and 235-239 (malignancies), 279 (congenital immunodeficiency) and V42 (organ or tissue replaced by transplant). The same case definition was used to identify $\mathrm{HZ}$ cases in the hospital-discharge registries.

\section{Case definitions used to identify PHN cases in the databases}

To capture PHN cases seen by a GP in the SIMG database who may not have been recoded from $\mathrm{HZ}$ to $\mathrm{PHN}$, patients were included if they had an ICD9-CM code for PHN (Table 1), or an ICD9-CM code for $\mathrm{HZ}$ and a prescription for any drug commonly prescribed for PHN, such as opioids, antiepileptics, tricyclic antidepressants (TCAs) or local anaesthetics (Table 2). Because there is no international consensus on the duration of pain in PHN, two definitions of PHN were used for cases identified in the SIMG database. PHN at 1 month (PHN1) or PHN at 3 months (PHN3) included all $\mathrm{HZ}$ cases that had been treated at least once with one or more of the aforementioned drugs during the period 112 months or 3-12 months after $\mathrm{HZ}$ diagnosis, respectively, or had an ICD9-CM PHN code recorded within the same time frame.

PHN cases were identified in the SDO databases as those with an ICD9-CM code for PHN (053.12, 053.13, or 053.19).

\section{Statistical analyses}

Estimates of $\mathrm{HZ}$ and proportion of patients with $\mathrm{HZ}$ developing PHN

As short-term recurrences of $\mathrm{HZ}$ are very uncommon among immunocompetent patients, all cases were assumed to be incident cases. Incidence of $\mathrm{HZ}$ was calculated as the number of cases in relation to the population at risk at the beginning of each calendar year (2003, $2004,2005)$, defined as the total patient population registered with the 342 primary-care practices. The proportion of patients with $\mathrm{HZ}$ who developed PHN (PHN1 or PHN3) was calculated. Estimates were obtained for immunocompetent patients aged $\geq 50$ years (primary analyses), for the whole adult population, and in relation to sex and immune status and by age group.

Table 2 Anatomical Therapeutic Chemical (ATC) Codes Used to Identify PHN Cases in the SIMG Database

\begin{tabular}{lll}
\hline ATC Code & Drug Class & Drugs \\
\hline N02A & Opioids & Tramadol \\
N03 & Antiepileptics & Phenytoin \\
& & Carbamazepine \\
& Gabapentin \\
& & Pregabalin \\
& & Amitriptyline \\
N06A & Antidepressants & Nortriptyline \\
& & Imipramine \\
& & Desipramine \\
& & Capsaicin cream \\
N01B & Local & Lidocaine \\
& anaesthetics &
\end{tabular}


The incidence in immunocompetent patients aged $\geq 50$ years (or incidence in the whole adult population) was extrapolated, by applying appropriate multiplication factors, to provide estimates of the annual number of cases of $\mathrm{HZ}$ or PHN for the total immunocompetent population aged $\geq 50$ years (or total adult population) in Italy. Population sizes were obtained from the Italian National Institute of Statistics (ISTAT) website [22].

Rates of hospitalisation for $\mathrm{HZ}$ and PHN (immunocompetent patients only) were calculated as the number of hospitalisations for $\mathrm{HZ}$ and $\mathrm{PHN}$, extracted from the SDOs, in relation to the population at risk. The population at risk constituted the resident population in each of the four regions, with figures obtained for the period 2003-2005 from the ISTAT website [22].

Univariate and multiple Poisson models, with age group, sex, immune status, region and calendar year as covariates, were used to identify factors associated with an increased risk of acquiring $\mathrm{HZ}$ and PHN. As assumed for a poisson model our response variable is a count variable [i.e., 0 no $\mathrm{HZ}$ (or 0 no $\mathrm{PHN}$ ), $1 \mathrm{HZ}$ (or PHN)]. For each year of the study period, each subject was considered exposed for the entire year. Crude and adjusted incidence rate ratios were estimated from these models given that the poisson regression coefficients are the logarithm of the rate ratio. Given that the study design was a two-stage design because data from primary care were clustered by GPs, and those from hospitalisations were clustered by region, the reported 95\% confidences intervals were calculated by taking into account the fact that people were clustered within GP practices (for the primary care data) and within region (for the hospitalisation data) [23]. The analyses were performed using Stata software (version 9.0).

Estimation of medical resource use and direct and indirect costs associated with $\mathrm{HZ}$ and PHN in immunocompetent patients aged $\geq 50$ years

Medical resource consumption for outpatient care in immunocompetent patients aged $\geq 50$ years was extracted from the SIMG database for the period 20032005. The follow-up period for cases of $\mathrm{HZ}$ was 1 month from diagnosis, while cases of PHN were followed for at least 6 months from initial diagnosis. Estimated unit costs for outpatient visits, diagnostic tests and procedures were based on the average actual cost of each visit/test/procedure across all individual records in the SIMG database in 2005. Costs of medication for $\mathrm{HZ}$ and PHN were calculated based on drug prices in the 2005 edition of the Prontuario Farmaceutico Nazionale (PFN) [24]. The amount of resource use and the unit costs were used to calculate the costs of outpatient care per episode of $\mathrm{HZ}$ and $\mathrm{PHN}$.

Medical resource consumption and costs for inpatient admissions and hospital day care between 2003 and
2005 in immunocompetent patients aged $\geq 50$ years were obtained from the hospital-discharge registries. Hospital costs were expressed in 2005 prices using the general price index before aggregating all direct costs.

The overall direct costs of $\mathrm{HZ}$ and $\mathrm{PHN}$ were calculated by multiplying the mean cost of each case with the expected total number of cases in the Italian population.

Indirect costs associated with $\mathrm{HZ}$ and $\mathrm{PHN}$ were based on likely productivity losses for individuals aged 50-64 years. A focus group of experts, including a neurologist, a geriatrist, a dermatologist and a pain specialist, led by an external moderator, reached a consensus on the number of working days lost due to $\mathrm{HZ}$ or PHN. Average daily wage data were taken from Consiglio Nazionale dell'Economia e del Lavoro (CNEL) labour cost statistics [25] and workforce participation rates from ISTAT data [22]. Indirect costs were expressed in 2005 prices using the general price index.

Estimates of the economic burden of $\mathrm{HZ}$ and $\mathrm{PHN}$ in the immunocompetent population aged $\geq 50$ years

Total cost per episode of $\mathrm{HZ}$ and PHN was estimated from both the third-party payer and societal perspective. The economic burden of $\mathrm{HZ}$ and PHN (calculation restricted to PHN1, as PHN1 and PHN3 were only distinguishable in the outpatient setting) was calculated as the sum of the estimated total outpatient costs, total hospitalisation costs, and total indirect costs (productivity loss) described above.

\section{Results \\ Epidemiological analysis \\ $\mathrm{HZ}$ incidence}

In total, 5675 incident cases of $\mathrm{HZ}$ were documented over the 3-year study period, with 1843, 1898 and 1934 cases recorded in 2003, 2004 and 2005, respectively. Patients aged $\geq 50$ years accounted for 4119 (72.6\%) incident cases, of which 3620 (87.9\%) occurred in immunocompetent patients. Among men and women aged $\geq 50$ years, this corresponded to an incidence of 6.65 per 1000 person-years (95\% CI: 6.35-6.97), or 6.31 per 1000 person-years (95\% CI: 6.01-6.62) in the immunocompetent population. In comparison, the incidence was 4.31 per 1000 person-years (95\% CI: 4.11-4.52) for the adult population as a whole, or 4.07 per 1000 person-years (95\% CI: 3.88-4.27) for the immunocompetent adult population. Incidence increased markedly with age, with the peak occurring in those aged 75-79 years (Figure 1). $\mathrm{HZ}$ was more common among women than men in the total population, with an incidence of 4.75 (95\% CI: 4.47-5.03) compared with 3.82 (95\% CI: 3.62-4.03) per 1000 person-years, respectively.

In the multivariate analysis, classical risk factors (female sex, age $\geq 55$ years, and being immunologically compromised) were found to be independently 


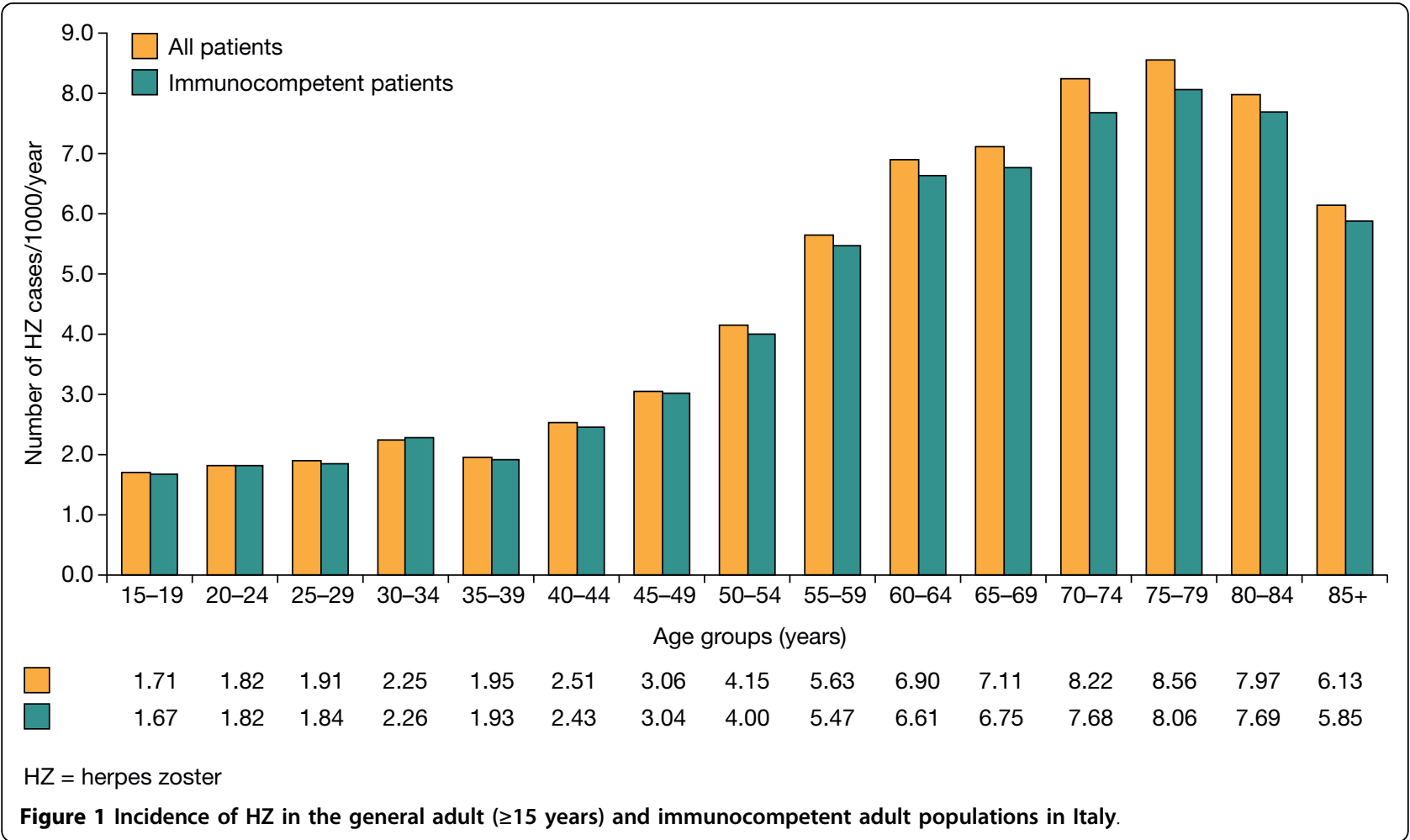

associated with an increased risk of acquiring $\mathrm{HZ}$ infection.

\section{Projected number of $\mathrm{HZ}$ cases per year}

With over 22 million people aged $\geq 50$ years living in Italy in 2005 [22], 139,435 new cases of HZ can be expected to occur annually in immunocompetent people aged $\geq 50$ years. A total of 157,100 cases would be expected in all people aged $\geq 50$ years, which represents $72.6 \%$ of the 216,391 cases expected for the adult population as a whole. Italian primary-care physicians, who have an average patient registry of 1283 , can expect to see between 5 and 6 new cases of HZ per year.

\section{Proportion of patients with $\mathrm{HZ}$ who developed PHN}

In total, 452 cases of PHN1 were documented in the adult population over the 3-year study period, of which $350(77.4 \%)$ cases also met criteria for PHN3. Thus, $8.0 \%(452 / 5675)(95 \%$ CI: 7.0-8.9) of the adult population with $\mathrm{HZ}$ experienced $\mathrm{PHN}$ lasting at least 1 month and 6.2\% (350/5675) (95\% CI: 5.3-7.0) experienced PHN for at least 3 months. The proportion of patients with $\mathrm{HZ}$ who developed PHN was highest in those aged $\geq 50$ years (Figure 2), with these older patients accounting for 91.2\% (412/452) of all cases of PHN1 and 90.9\% (318/ 350) of all cases of PHN3. The PHN1 proportion and PHN3 proportion were similar for all $\mathrm{HZ}$ patients aged $\geq 50$ years (10.0\% [412/4119] [95\% CI: 8.8-11.2] and 7.7\% [318/4119] [95\% CI: 6.6-8.8], respectively) and the immunocompetent $\mathrm{HZ}$ patients aged $\geq 50$ years $(9.4 \%$
[342/3620] [95\% CI: 8.2-10.7] and 7.2\% [261/3620] [95\% CI: 6.2-8.2], respectively).

PHN was more common in women than in men with HZ. In the adult population as a whole, the proportion of women vs. men with $\mathrm{HZ}$ who developed PHN was $8.9 \%(294 / 3296)$ (95\% CI: 7.7-10.2) vs. 6.6\% (158/2379) (95\% CI: 5.5-7.7) for PHN1 and 6.9\% (228/3296) (95\% CI: $5.8-8.0)$ vs. $5.1 \%(122 / 2379)$ (95\% CI: 4.1-6.1) for PHN3. Over 65\% of cases of both PHN1 and PHN3 in primary care were documented in female patients.

In the multivariate analysis, classical risk factors (female sex, increasing age [ $>60$ years], and being immunologically compromised) were found to be independently associated with an increased risk of developing PHN.

\section{Hospitalisation for $\mathrm{HZ}$ and $\mathrm{PHN}$}

Over the 3-year study period, the average incidences of hospitalisation for primary diagnoses of $\mathrm{HZ}$ and $\mathrm{PHN}$ were 10.34 and 1.89 per 100,000 person-years, respectively, in immunocompetent patients aged $\geq 50$ years. The total incidence rose to 20.31 per 100,000 personyears (17.45 for HZ and 2.86 for PHN) in this population when both primary and secondary diagnoses on SDOs were combined. Corresponding figures for the adult immunocompetent population as a whole were 5.55 per 100,000 person-years for a primary diagnosis (4.61 for HZ and 0.94 for PHN) and 9.60 per 100,000 person-years for primary and secondary diagnoses 


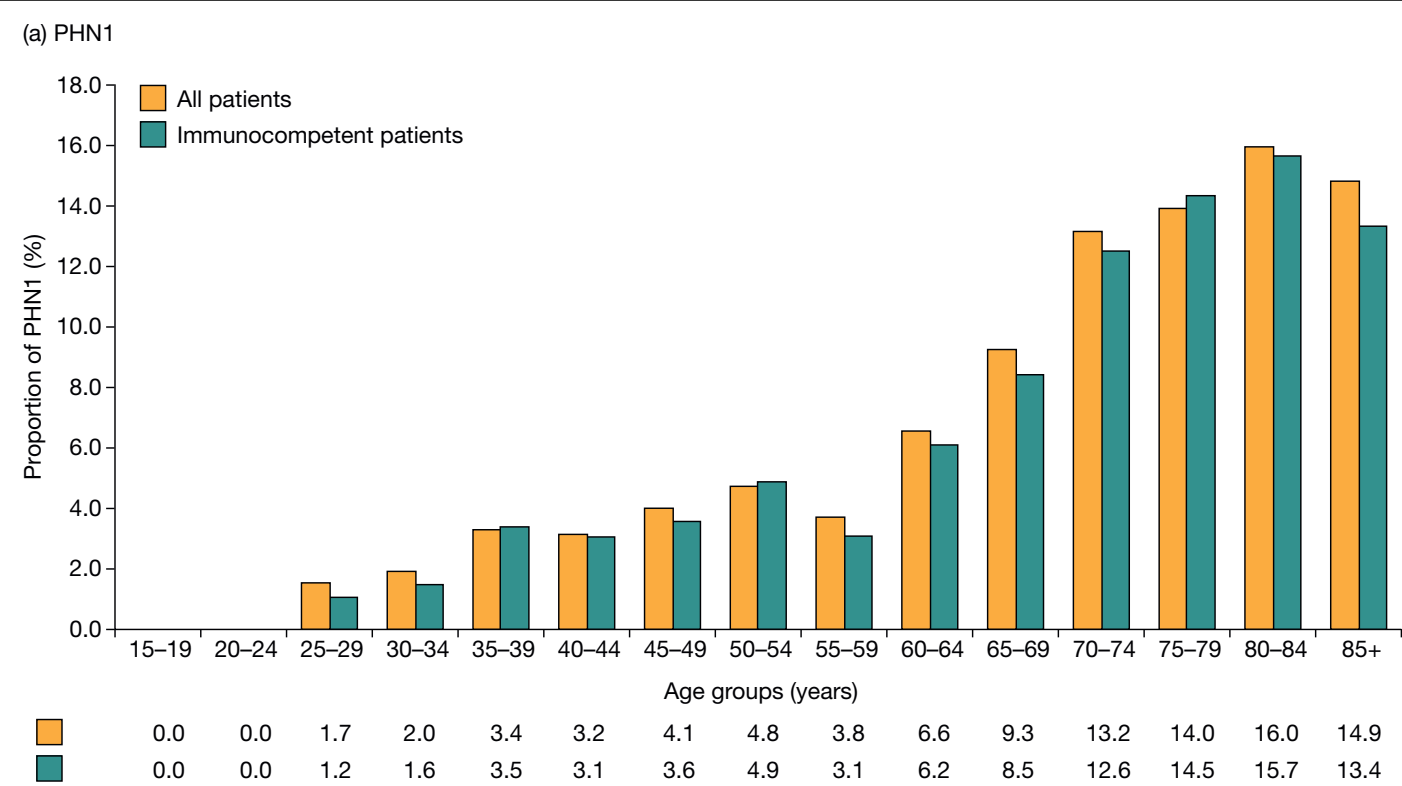

(b) PHN3

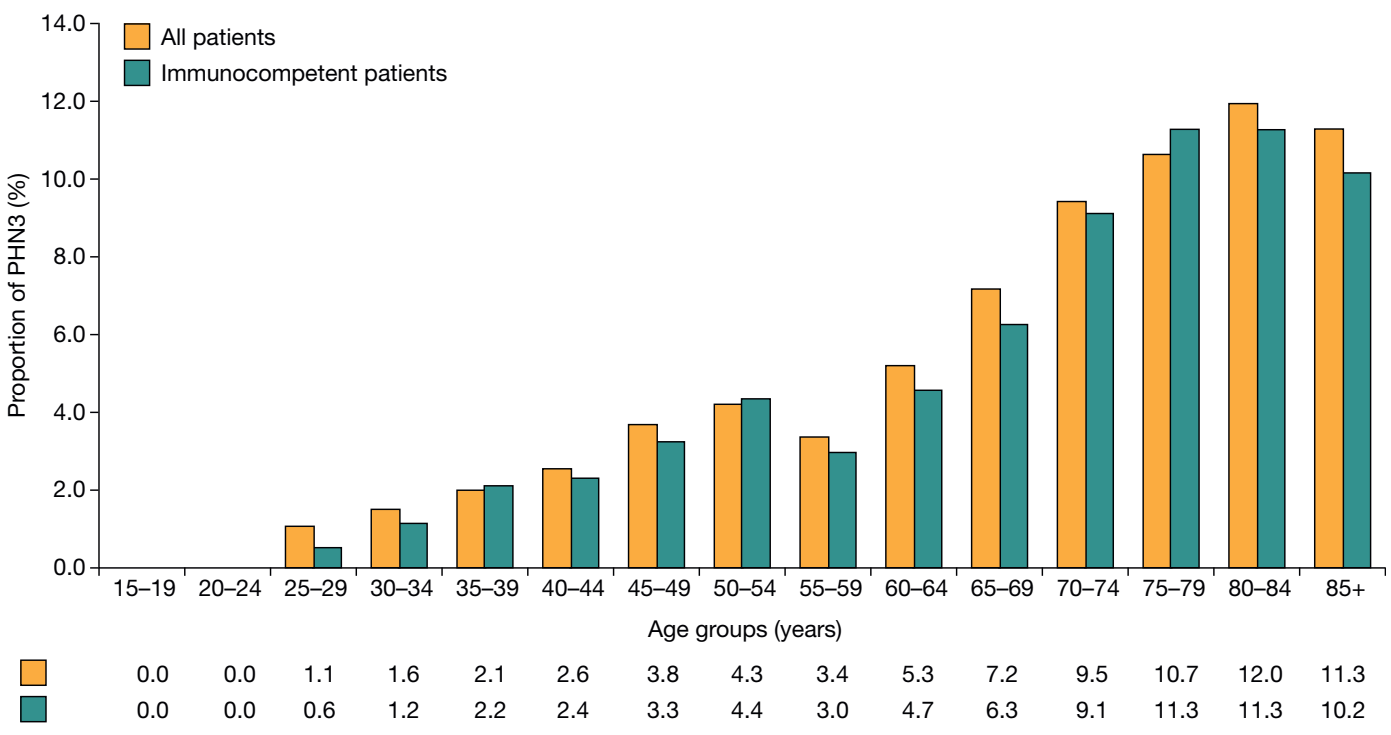

$\mathrm{PHN}=$ post-herpetic neuralgia

Figure 2 Proportion of PHN in the general adult ( $\geq 15$ years) and immunocompetent adult populations in Italy.

combined (7.94 for HZ and 1.66 for PHN). Within the older population, rates of hospitalisation increased progressively for each decade up to 85 years (Figure 3). Based on these figures, $\mathrm{HZ}$ or PHN as a primary diagnosis is responsible for 2829 hospitalisations annually in Italy among the immunocompetent adult population, of which 2611 (92.3\%) admissions are in those aged $\geq 50$ years. When primary and secondary diagnoses are combined, about $1.3 \%$ of $\mathrm{HZ}$ cases in Italy result in hospitalisation, rising to almost $2 \%$ where patients develop
PHN. Overall, $16.9 \%$ of hospitalisations related to $\mathrm{HZ}$ were due specifically to PHN.

\section{Economic analysis Outpatient resource consumption}

For immunocompetent patients aged $\geq 50$ years, the mean number of primary-care consultations for each case of $\mathrm{HZ}$ was 1.9. In total, 17.7\% (640/3620) of cases were referred to a specialist (primarily ophthalmologists, dermatologists or neurologists). The mean number of 


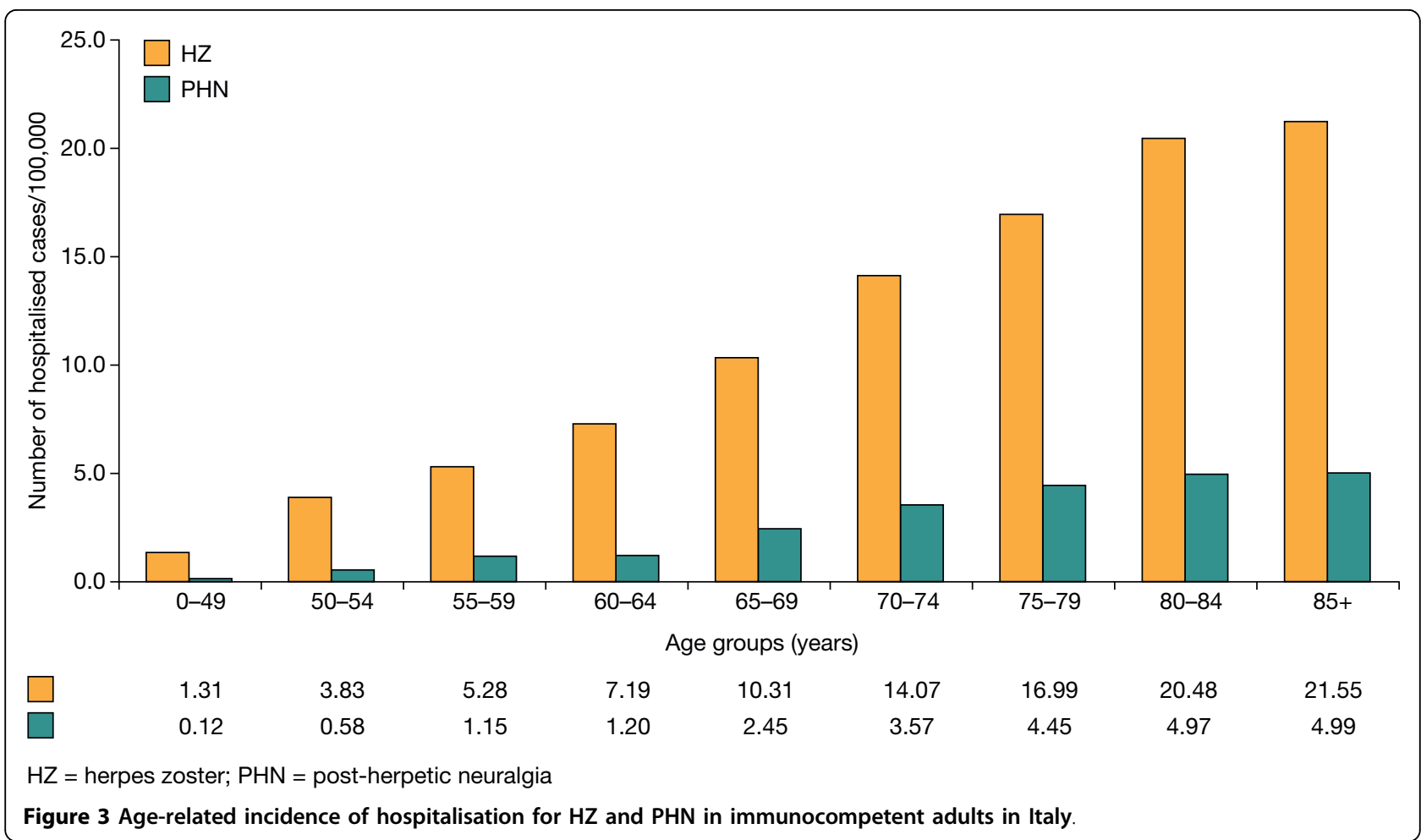

specialist visits was 0.2 for each case of $\mathrm{HZ}$, increasing slightly with age. Antivirals were used in $78.4 \%$ of cases, while $12.2 \%$ were treated with anticonvulsants, $5.1 \%$ with opioid analgesics, $3.2 \%$ with non-opioid analgesics and $3.0 \%$ with TCAs. Overall, $28.0 \%(1012 / 3620)$ of cases underwent further diagnostic or laboratory examinations, with the mean number of procedures and examinations being 2.6 for each case of $\mathrm{HZ}$, increasing with age (age class range 2.3-2.9).

For immunocompetent patients aged $\geq 50$ years, the mean number of primary-care consultations for each case of PHN1 and PHN3 was 11.9 and 12.0, respectively. In total, $74.1 \%(206 / 278)$ and $73.7 \%$ (154/209) of PHN1 and PHN3 cases were referred to a specialist (primarily ophthalmologists, dermatologists or neurologists), with a mean number of specialist visits of 3.5 for each case of PHN1 (age class range 2.2-4.3) and 3.9 for each case of PHN3 (age class range 2.5-4.7). Anticonvulsants were prescribed in $51.4 \%$ and $46.4 \%$ of PHN1 and PHN3 cases, respectively. Corresponding figures for opioid analgesics were $27.0 \%$ and $26.3 \%$ and for TCAs were $15.1 \%$ and $13.4 \%$, respectively. Drug utilisation was higher overall for cases of PHN3.

\section{Direct costs - outpatient care}

For immunocompetent patients aged $\geq 50$ years, the mean outpatient cost $( \pm \mathrm{SD})$ for each case of $\mathrm{HZ}$ was $€ 122.68 \pm € 97.51$ (at 2005 prices), of which $83.1 \%$ was due to the cost of medications. Diagnostic radiology or ophthalmological and otological examinations (6.8\%), laboratory investigations $(6.6 \%)$ and specialist visits (3.6\%) accounted for the remaining costs.

For immunocompetent patients aged $\geq 50$ years, the mean outpatient cost $( \pm S D)$ for each case of PHN1 was $€ 446.10 \pm € 442.97$ and for each case of PHN3 was $€ 416.65 \pm € 406.30$ (at 2005 prices), of which laboratory investigations and investigative procedures accounted for $58.1 \%$ and $63.4 \%$ of total costs for PHN1 and PHN3, respectively. Medications accounted for about a quarter of total outpatient costs, at $27.7 \%$ and $21.5 \%$ for PHN1 and PHN3, respectively. Specialist referral was sought in $74.1 \%(206 / 278)$ of PHN1 cases and $73.7 \%(154 / 209)$ of PHN3 cases; these visits accounted for the remaining $14.2 \%$ and $15.1 \%$, respectively, of total outpatient costs.

\section{Hospital resource consumption}

Of the total hospitalisations for HZ, 92.3\% were related to major skin disorders, eye disorders, infections of the nervous system (excluding meningitis) and viral illnesses. For immunocompetent patients aged $\geq 50$ years, the mean $( \pm \mathrm{SD})$ inpatient stay for $\mathrm{HZ}$ was $7.8 \pm 5.4$ days, which increased with age (6.5 \pm 5.5 days for 50 54 -year-olds vs. $8.9 \pm 5.6$ days for those aged $>85$ years). Of the total hospitalisations for patients with PHN, 92.6\% were related to cranial and peripheral nerve disorders and infections of the nervous system (excluding meningitis). For immunocompetent patients aged $\geq 50$ 
years, the mean $( \pm S D)$ inpatient stay for PHN was 10.2 \pm 8.6 days and showed no age-related trend.

\section{Direct costs - inpatient care}

For immunocompetent patients aged $\geq 50$ years who were hospitalised, the mean cost $( \pm$ SD) per patient of inpatient care in the period 2003-2005 was €2592 \pm $€ 1313$ for $\mathrm{HZ}$ and $€ 2806 \pm € 2641$ for PHN.

\section{Total direct costs per case}

The mean direct medical cost per $\mathrm{HZ}$ episode in Italy was calculated as $€ 166$, which comprised outpatient costs of $€ 123$ per episode, to which $€ 43$ was added as the mean cost of hospitalisation per $\mathrm{HZ}$ episode, computed as the cost of hospitalisation spread over the total number of expected cases (Table 3). The corresponding mean direct medical cost of PHN (calculation restricted to PHN1, as PHN1 and PHN3 were only distinguishable in the outpatient setting) was calculated as $€ 560$ per episode (Table 3).

\section{Indirect costs per case}

Mean indirect costs for the immunocompetent population aged $\geq 50$ years were based on the following assumptions: a workforce participation rate of $65.8 \%$ for 50-54-year-olds declining to $20.2 \%$ for $60-64$-year-olds and retirement at 65 years; an average daily wage of $€ 80$; and an average loss of 7 and 10 working days for $\mathrm{HZ}$ and $\mathrm{PHN}$, respectively. Indirect costs were calculated at $€ 556$ and $€ 795$ per case of $\mathrm{HZ}$ and $\mathrm{PHN}$, respectively (Table 3 ).

\section{Total costs}

Based on an estimated 129,435 cases of $\mathrm{HZ}$ and 12,228 cases of PHN1 per annum in the immunocompetent population aged $\geq 50$ years, the total direct medical cost of managing $\mathrm{HZ}$ infection and PHN in Italy was $€ 28.2$ million, of which $€ 21.5$ million was associated with the treatment of acute $\mathrm{HZ}$ (Table 3). Outpatient costs accounted for $75.2 \%$ of the total expenditure. Total indirect costs were calculated as $€ 13.0$ million, of which $€ 12.2$ million was attributed to acute $\mathrm{HZ}$ (Table 3 ). The total annual economic burden of $\mathrm{HZ}$ and associated $\mathrm{PHN}$ in the Italian immunocompetent population aged $\geq 50$ years was $€ 41.2$ million, with almost a third of the cost attributable to indirect costs associated with lost productivity.

\section{Discussion}

This retrospective, population-based study represents the largest investigation to date of the epidemiology and economic impact of $\mathrm{HZ}$ and PHN in Italy. Drawing on a primary-care database of over 450,000 patient records, together with data from national hospital-discharge records covering four major regions in Italy, our study showed that the incidence of $\mathrm{HZ}$ in immunocompetent individuals aged $\geq 50$ years (6.31 per 1000 person-years), the primary focus of the study, was comparable with that reported in other studies $[8,26]$, including an earlier Italian study [18]. Furthermore, the incidence reported here was consistent with recently published figures, for the population aged $\geq 50$ years, from the UK (5.23 per 1000 person-years) [6] and Australia (9.7 per 1000 person-years) [7] despite some differences in study design. However, our overall $\mathrm{HZ}$ incidence is higher than the one recently published in Italy (4.31 vs. 1.59 per 1000 person-years) [19]. In common with these studies, HZ incidence increased markedly with age up to 80 years. In Italy, most patients with $\mathrm{HZ}$ consult their primarycare physician [18] and so our data, retrieved from the SIMG database, can be considered a reliable and robust source for estimates of $\mathrm{HZ}$ incidence.

$\mathrm{HZ}$ incidence was more common in women than men, a finding supported by several other studies [6,26-28], albeit not all $[4,29]$. In addition to older age and immune status, female sex was an independent risk factor for $\mathrm{HZ}$, and indeed, for PHN as well. It is known that immunosuppression predisposes patients to increased risk of $\mathrm{HZ}$ and its complications [30]. It has been suggested that women may have a different immune response to latent viral infection and that this may account for their increased risk compared with men [27].

PHN, which in our study was identified by ICD9-CM codes or prescriptions for specific neuropathic pain medications, affected $9.4 \%$ of immunocompetent

Table 3 Costs Associated with HZ and PHN in Immunocompetent Patients Aged $\geq 50$ years (at 2005 prices)

\begin{tabular}{|c|c|c|c|c|c|}
\hline & $\mathrm{HZ}$ & PHN & $\mathrm{HZ}$ plus $\mathrm{PHN}$ & & \\
\hline \multirow[t]{2}{*}{ Number of expected cases in Italian population per year } & 129,435 & 12,228 (PHN1 only*) & & & \\
\hline & Mean $€$ & Total $€ m$ & Mean $€$ & Total $€ m$ & Total $\in \mathrm{m}$ \\
\hline Direct outpatient costs & 123 & 15.9 & 446 & 5.3 & 21.2 \\
\hline Direct hospital costs & 43 & 5.6 & 114 & 1.4 & 7.0 \\
\hline Total direct costs & 166 & 21.5 & 560 & 6.7 & 28.2 \\
\hline Indirect costs & 556 & 12.2 & 795 & 0.8 & 13.0 \\
\hline Total costs & & 33.7 & & 7.5 & 41.2 \\
\hline
\end{tabular}

$\mathrm{HZ}=$ herpes zoster; $\mathrm{PHN}=$ post-herpetic neuralgia

* Restricted to PHN1 because PHN1 and PHN3 were only distinguishable in the outpatient setting 
patients aged $\geq 50$ years, of whom about $77 \%$ continued to have pain 3 months after $\mathrm{HZ}$ onset. These rates are consistent with those reported for several other community-based studies [31-33]. However, they are considerably lower than rates reported in clinical trials [34-36], in other various studies $[8,26]$ and, interestingly, in a recent prospective study conducted in Piemonte in Italy [19] and the recent UK General Practice Research Database (UKGPRD) analysis [6], where $17.4 \%$ and $19.5 \%$ of patients developed PHN1, respectively.

Certain limitations of this study may have resulted in an underestimation of the proportion of PHN. In Italy, primary-care physicians manage most cases of $\mathrm{HZ}$ but only about a quarter of related cases of PHN because most cases of PHN are managed by specialists. Thus, this study did not capture cases of PHN that were not seen by a primary-care physician or referred to hospital. This demonstrates that use of the SIMG database to evaluate PHN in Italy has limits as it excludes patients who may have approached specialists directly. In addition, estimating the number of PHN cases retrospectively on the basis of drug prescriptions for pain relief rather than on the basis of pain severity may have led to an underestimation of the proportion of $\mathrm{HZ}$ cases that developed PHN because less serious cases which were not treated with drugs and serious cases where patients refused drug treatment may not have been detected. While our estimates of $\mathrm{HZ}$ incidence are robust, those for the proportion of patients with $\mathrm{HZ}$ who developed PHN are less reliable and are probably underestimates. Indeed, it is arguable that no study has produced reliable estimates of the proportion of $\mathrm{HZ}$ cases that develop PHN, and this is exemplified by the variation seen between studies $[6,19,26,34,35]$. Furthermore, in retrospective studies based on data retrieved from large databases, inaccuracies and, therefore, underestimations due to incompleteness of data cannot be excluded. Prospective studies, with patient follow-up, would provide a more reliable approach to future estimates of the proportion of patients with $\mathrm{HZ}$ developing PHN.

Some patients with $\mathrm{HZ}$ and PHN require hospital treatment, including inpatient care. Overall, about $1.3 \%$ of $\mathrm{HZ}$ cases required inpatient care in this study, increasing to almost $2 \%$ where only PHN cases were considered. At 9.60 per 100,000 person-years, the incidence of hospitalisations for $\mathrm{HZ}$ or PHN was higher in our study than rates reported in other European countries or North America [37,38] despite the exclusion in our study of immunocompromised patients who constitute those at greater risk of complications of HZ. In the recent prospective study in Piemonte, the annual incidence of hospitalisations for $\mathrm{HZ}$ was 0.12 per 1000 population [19]. Similar to the Piemonte study, age was an important predictor of likely hospitalisation for $\mathrm{HZ}$ or PHN in our study, with rates of hospitalisation increasing progressively for each decade up to 85 years of age, an observation that has also been reported previously [7]. Our data show a striking age-related increase in hospitalisation due to both $\mathrm{HZ}$ and PHN whether as a primary or secondary diagnosis.

We also estimated the economic impact of $\mathrm{HZ}$ and its complications in terms of direct healthcare costs as well as estimating likely indirect costs. As this study has demonstrated, $\mathrm{HZ}$ and PHN, the most common complication of HZ, impose a significant economic burden on the Italian population, with total costs for patients aged $\geq 50$ years exceeding $€ 41$ million a year. At $€ 28.2$ million, direct medical costs accounted for just over two-thirds of total costs. Indirect costs associated with lost productivity were responsible for almost a third of total costs in the older population and reflect the debilitating nature of HZ and PHN among older people of working age. Although the recent prospective study in Piemonte did not extrapolate data to obtain total direct costs for the Italian population, at $€ 136.06$ per observed outpatient case of HZ, $€ 360.60$ per case treated in the outpatient setting, and $€ 4082.59$ for each hospitalised case (€2499.67 where $\mathrm{HZ}$ was the principal diagnosis) direct costs per case were broadly similar to our estimates [19].

Studies have consistently shown that $\mathrm{HZ}$ and especially PHN significantly impact patients' quality of daily life [9-14] and, moreover, are difficult to treat. Therapy relies on antiviral drugs to address the underlying cause of $\mathrm{HZ}$ and analgesia for pain relief in patients who develop PHN. As this study has shown, medications were responsible for over $80 \%$ of all direct outpatient costs, a finding supported by other studies [6,39]. This primary cost determinant may vary widely between countries. In the present study $78 \%$ of patients received antivirals, similar to the proportion reported for a recent study in Australia, whereas less than 25\% of patients with $\mathrm{HZ}$ in The Netherlands receive antiviral therapy $[7,40]$. If administered within 72 hours of the onset of rash, antivirals have been shown to promote rash healing and reduce the intensity and pain of acute $\mathrm{HZ}$ $[35,41]$. However, a recent Cochrane Review found no evidence for an impact of antiviral therapy on PHN, with their efficacy for prevention of PHN considered modest at best [42].

Previously, it has been shown that patients requiring hospitalisation are likely to have more severe $\mathrm{HZ}$ or PHN, and thus, hospital-discharge data provide a measure of more serious cases [2]. In the present study, direct costs associated with inpatient care for an $\mathrm{HZ}$ case were more than 20 times the cost for outpatient care. In comparison, direct costs associated with inpatient care for a PHN episode were more than five times the cost for outpatient care. This illustrates the 
substantial costs associated with the management of more serious cases of $\mathrm{HZ}$ and PHN, where patients may require hospital care.

It is difficult to make direct comparisons between the present study and studies carried out in other countries to assess direct and indirect costs associated with $\mathrm{HZ}$ and PHN because of differences in healthcare practices and pricing. Nonetheless, as others have concluded, the economic and social costs of managing $\mathrm{HZ}$ and its complications represent an important burden on healthcare services and society [43], a view with which we would concur.

Our study had a number of limitations in addition to those already discussed. The higher percentage of home consultations in the very elderly, which may not have been recorded in the SIMG database, may have led to underestimation of incidence in the very old. Hospitaldischarge data do not state unequivocally that $\mathrm{HZ}$ or PHN was the initial reason for hospitalisation, which may have affected the estimates of disease burden. As GP prescriptions could not be linked to specific PHN diagnostic codes and the drugs may have been prescribed for conditions other than PHN, outpatient costs for PHN may have been overestimated. Indirect costs were based solely on productivity losses due to absence from work and were derived from expert opinion, an approach that may limit the reliability of indirect cost estimates. Experts agreed that $\mathrm{HZ}$ patients will usually loose between 7 and 10 working days, while in case of serious pain 10-15 working days are reasonably lost due to PHN. Accordingly, the conservative assumption of 7 and 10 working days lost due to $\mathrm{HZ}$ and PHN, respectively, was made in the estimate of indirect costs. However, all focus group specialists stressed the extreme variability of the non-acute phase. Finally, when combining the results from the epidemiological and economic parts of the study it was not possible to obtain a measure of the reliability of estimates of the total cost of $\mathrm{HZ}$ and PHN (covariance between the different components of the total variability was unknown).

\section{Conclusions}

In conclusion, this study has demonstrated that $\mathrm{HZ}$ and related complications such as PHN impose a considerable disease and economic burden in Italy. While our estimates of $\mathrm{HZ}$ incidence in the Italian population can be considered robust, those for the proportion of patients with $\mathrm{HZ}$ who develop PHN are likely to be underestimates and would best be assessed in prospective studies. As HZ and PHN disproportionately affect the elderly, without intervention the burden to patients and society is likely to grow as the proportion of elderly in the Italian population continues to increase.

\section{Acknowledgements}

The authors would like to thank: Karine Barthe, Sanofi Pasteur MSD, Lyon, France and Dario Corsini, Informa, Rome, Italy for their help in coordinating the study; Giuliano Ferrucci and Laura Timelli, Informa, Rome, Italy for their help with the statistical analyses; Annette Schrauder for help with the conduct of the study. The authors take full responsibility for the content of the paper but thank Communigen (supported by Sanofi Pasteur MSD) for editorial assistance in preparing the manuscript.

\section{Author details}

Dipartimento di Sanità Pubblica, Università di Roma Tor Vergata, Via Montpellier 1, 00133, Roma, Italy. ' Informa srl, via del Commercio 36, 00154, Roma, Italy. ${ }^{3}$ Centro Studi GISED, Ospedali Riuniti, 24128, Bergamo, Italy. ${ }^{4}$ Università degli Studi di Roma Tor Vergata, Fondazione Policlinico Tor Vergata Viale Oxford n 81, 00133 Roma, Italia. ${ }^{5}$ Sanofi Pasteur MSD, 8, rue Jonas Salk, 69367, Lyon, France. 'Sanofi Pasteur MSD, Via degli

Aldobrandeschi, 1500163 Rome, Italy.

\section{Authors' contributions}

LEG participated in the study design, analysis of data and drafting of the study report and helped to draft the manuscript. MM and PP participated in the study design and analysis of data. LN, AG and AV validated the protocol, design and final results of the study. MB, LS and RM participated in the study design, coordinated the study and validated the study results and study report. All authors read and approved the final draft manuscript.

\section{Competing interests}

LN provided consultancy advice to Sanofi Pasteur MSD to assist with developing the study. AG has provided consultancy advice to Sanofi Pasteur MSD. AV has provided consultancy advice to Sanofi Pasteur MSD and Novartis, and has received honoraria for lectures from these companies and from GlaxoSmithKline and Menarini. He has also received honoraria for preparing educational materials for Menarini. LEG, MM and PP are consultants for Informa, Rome, who coordinated this study. MB, LS and RM are employees of Sanofi Pasteur MSD, a provider of a herpes zoster vaccine approved in the European Union.

Received: 8 June 2009 Accepted: 3 August 2010

Published: 3 August 2010

\section{References}

1. Bowsher D: The lifetime occurrence of herpes zoster and prevalence of postherpetic neuralgia: a retrospective survey in an elderly population. Eur J Pain 1999, 3:335-342.

2. Edmunds WJ, Brisson M, Rose JD: The epidemiology of herpes zoster and potential cost-effectiveness of vaccination in England and Wales. Vaccine 2001, 19:3076-3090.

3. Brisson M, Edmunds WJ, Law B, Gay NJ, Walld R, Brownell M, Roos L, De Serres G: Epidemiology of varicella zoster virus infection in Canada and in the United Kingdom. Epidemiol Infect 2001, 127:305-314.

4. Donahue JG, Choo PW, Manson JE, Platt R: The incidence of herpes zoster. Arch Intern Med 1995, 155:1605-1609.

5. Levin MJ, Smith JG, Kaufhold RM, Barber D, Hayward AR, Chan CY, Chan IS, Li DJ, Wang W, Keller PM, Shaw A, Silber JL: Decline in varicella-zoster virus (VZV)-specific cell-mediated immunity with increasing age and boosting with a high-dose VZV vaccine. J Infect Dis 2003, 188:1336-1344.

6. Gauthier A, Breuer J, Carrington D, Martin M, Remy V: Epidemiology and cost of herpes zoster and post-herpetic neuralgia in the United Kingdom. Epidemiol Infect 2009, 137:38-47.

7. Stein AN, Britt H, Harrison C, Conway EL, Cunningham A, Macintyre CR: Herpes zoster burden of illness and health care resource utilization in the Australian population aged 50 years and older. Vaccine 2009, 27:520-529.

8. Yawn BP, Saddier P, Wollan PC, St. Sauver JL, Kurland MJ, Sy LS: A population-based study of the incidence and complication rates of herpes zoster before zoster vaccination introduction. Mayo Clin Proc 2007, 82:1341-1349.

9. Volpi A, Gatti A, Pica F, Bellino S, Marsella LT, Sabato AF: HYPERLINK "[http://www.ncbi.nlm.nih.gov/pubmed/18649332? ordinalpos=7\&itool=EntrezSystem2.PEntrez.Pubmed. Pubmed_ResultsPanel.Pubmed_DefaultReportPanel. 
Pubmed_RVDocSum]" Clinical and psychosocial correlates of postherpetic neuralgia. J Med Virol 2008, 80:1646-1652.

10. Oster G, Harding G, Dukes E, Edelsberg J, Cleary P: Pain, medication use, and health-related quality of life in older persons with postherpetic neuralgia: results from a population-based survey. J Pain 2005, 6:356-363.

11. Katz J, Cooper E, Walther R, Sweeney E, Dworkin R: Acute pain in herpes zoster and its impact on health-related quality of life. Clin Infect Dis 2004, 39:342-348.

12. Brisson M, Pellissier JM, Camden S, Quach C, De Wals P: The potential costeffectiveness of vaccination against herpes zoster and post-herpetic neuralgia. Hum Vaccin 2008, 4:238-245.

13. Schmader KE: Epidemiology and impact on quality of life of postherpetic neuralgia and painful diabetic neuropathy. Clin J Pain 2002, 18:350-354.

14. Schmader KE, Sloane R, Pieper C, Coplan PM, Nikas A, Saddier P, Chan I, Choo P, Levin MJ, Johnson G, Williams HM, Oxman MN: The impact of acute herpes zoster pain and discomfort on functional status and quality of life in older adults. Clin J Pain 2007, 23:490-496.

15. Volpi A, Gross G, Hercogova J, Johnson RW: Current management of herpes zoster. The European view. Am J Clin Dermatol 2005, 6:317-325.

16. Johnson RW, Wasner G, Saddier P, Baron R: Herpes zoster and postherpetic neuralgia: optimizing management in the elderly patient. Drugs Aging 2008, 25:991-1006.

17. United Nations Population Division: World Population Prospects: The 2006 Revision Population Database. [http://esa.un.org/unpp/], accessed 11 March 2009.

18. Di Luzio Paparatti U, Arpinelli F, Visona G: Herpes zoster and its complications in Italy: an observational survey. J Infect 1999, 38:116-119.

19. Di Legami V, Gianino MM, Atti MCD, Massari M, Migliardi A, Tomba GS, Zotti C, Zoster Study Group: Epidemiology and costs of herpes zoster: background data to estimate the impact of vaccination. Vaccine 2007, 25:7598-7604

20. Filippi A, Bignamini AA, Sessa E, Samani F, Mazzaglia G: Secondary prevention of stroke in Italy: a cross-sectional survey in family practice. Stroke 2003, 34:1010-1014.

21. Filippi A, Sabatini A, Badioli L, Samani F, Mazzaglia G, Catapano A, Cricelli C: Effects of an automated electronic reminder in changing the antiplatelet drug-prescribing behaviour among General Practitioners in Italy in diabetic patients: an intervention trial. Diabetes Care 2003, 26:1497-1500,

22. Italian National Institute of Statistics (ISTAT). , [HYPERLINK "http://www. demo.istat.it"]; accessed 11 March 2009.

23. Leyland $\mathrm{AH}$, Goldstein H: Multilevel Modelling of Health Statistics Chichester Wiley 2001.

24. Italian Medicines Agency (Agenzia Italiana del Farmaco; AIFA): Prontuario Farmaceutico Nazionale (PFN). Italy. 2005.

25. Consiglio Nazionale dell'Economia e del Lavoro, Banca dati su costo, retribuzioni e orario di lavoro. , [HYPERLINK "http://www.portalecnel.it/" http://www.portalecnel.it/; accessed 11 March 2009.

26. Chidiac C, Brucelle J, Daures J-P, Hoang-Xuan T, Morel P, Leplege A, E Hasnaoui A, de Labareyer C: Characteristics of patients with herpes zoster on presentation to practitioners in France. Clin Infect Dis 2001, 33:62-69.

27. Fleming DM, Cross KW, Cobb WA, Chapman RS: Gender difference in the incidence of shingles. Epidemiol Infect 2004, 132:1-5.

28. Opstelten W, Van Essen GA, Schellevis F, Verheij TJM, Moons KGM: Gender as an independent risk factor for herpes zoster: a population-based prospective study. Ann Epidemiol 2006, 16:692-695.

29. Schmader K, Gorge LK, Burchett BM, Pieper CF, Hamilton JD: Racial differences in the occurrence of herpes zoster. J Infect Dis 1995, 171:701-704

30. Gross G, Schöfer H, Wassilew S, Friese K, Timm A, Guthoff R, Pau HW, Malin JP, Wutzler P, Doerr HW: Herpes zoster guideline of the German Dermatology Society (DDG). J Clin Virol 2003, 26:277-289.

31. Oxman MN: Clinical manifestations of herpes zoster. Varicella-zoster Virus: Virology and Clinical Management Cambridge, UK: Cambridge University PressArvin AM, Gershon AA 2000, 246-275.

32. Chen TM, Gorge S, Woodruff CA, Hsu S: Clinical manifestations of varicella-zoster virus infection. Dermatol Clin 2002, 20:267-282.

33. Choo PW, Galil K, Donahue JG, Walker AM, Spiegelman D, Platt R: Risk factors for post herpetic neuralgia. Arch Intern Med 1997, 157:1217-1224.

34. Dworkin RH, Boon RJ, Griffin DR, Phung D: Postherpetic neuralgia: impact of famciclovir, age, rash severity and acute pain in herpes zoster patients. J Infect Dis 1998, 178(Suppl 1):76S-80S
35. Wood MJ, Kay R, Dworkin RH, Soong SJ, Whitley RJ: Oral acyclovir therapy accelerates pain resolution in patients with herpes zoster: a metaanalysis of placebo-controlled trials. Clin Infect Dis 1996, 22:341-347.

36. Oxman MN, Levin MJ, Johnson GR, Schmader KE, Straus SE, Gelb LD, Arbeit RD, Simberkoff MS, Gershon AA, Davis LE, Weinberg A, Boardman KD, Williams HM, Hongyuan Zhang J, Peduzzi PN, Beisel CE, Morrison VA, Guatelli JC, Brooks PA, Kauffman CA, Pachucki CT, Neuzil KM, Betts RF, Wright PF, Griffin MR, Brunell P, Soto NE, Marques AR, Keay SK, Goodman RP, Cotton DJ, Gnann JW, Loutit J, Holodniy M, Keitel WA, Crawford GE, Yeh S-S, Lobo Z, Toney JF, Greenberg RN, Keller PM, Harbecke R, Hayward AR, Irwin MR, Kyriakides TC, Chan CY, Chan ISF, Wang WWB, Annuziato PW, Silber JL, for the Shingles Prevention Study Group: A vaccine to prevent herpes zoster and postherpetic neuralgia in older adults. N Engl J Med 2005, 352:2271-2284.

37. Brisson M, Edmunds WJ: Epidemiology of varicella-zoster virus in England and Wales. J Med Virol 2003, 70(Suppl 1):S9-S14.

38. Gil A, San-Martin M, Carrasco P, Gonzales A: Epidemiology of severe varicella-zoster virus infection in Spain. Vaccine 2004, 22:3947-3951.

39. Scott FT, Johnson RW, Leedham-Green M, Davies E, Edmunds WJ, Breuer J: The burden of herpes zoster: A prospective population based study. Vaccine 2006, 24:1308-1314

40. Opstelten W, van Essen GA, Mons KGM, van Wijck AJM, Schellevis FG, Kalkman CJ, Verheij TJM: Do herpes zoster patients receive antivirals? A Dutch national survey in general practice. Family Practice 2005, 22:523-528.

41. Wood MJ, Shukla S, Fiddian AP, Crooks RJ: Treatment of acute herpes zoster: effect of early $(<48 \mathrm{~h}$ ) versus late (48-72 h) therapy with acyclovir and valacicolvir on prolonged pain. J Infect Dis 1998, 178(Suppl 1): S81-S84.

42. Li Q, Chen N, Yang J, Zhou D, Zhang Q, He L: Antiviral treatment for preventing postherpetic neuralgia. Cochrane Database Syst Rev 2009, 2 CD006866.

43. Wareham DW, Breuer J: Herpes zoster. BMJ 2007, 334:1211-1215.

\section{Pre-publication history}

The pre-publication history for this paper can be accessed here: http://www.biomedcentral.com/1471-2334/10/230/prepub

doi:10.1186/1471-2334-10-230

Cite this article as: Gialloreti et al:: Epidemiology and economic burden of herpes zoster and post-herpetic neuralgia in Italy: A retrospective, population-based study. BMC Infectious Diseases 2010 10:230.

\section{Submit your next manuscript to BioMed Central and take full advantage of:}

- Convenient online submission

- Thorough peer review

- No space constraints or color figure charges

- Immediate publication on acceptance

- Inclusion in PubMed, CAS, Scopus and Google Scholar

- Research which is freely available for redistribution
C Biomed Central 